\title{
Pengembangan Taman Baca Digital Sebagai Sumber Belajar Bagi Masyarakat Pesona 2 Cilebut Barat - Kabupaten Bogor
}

\author{
Fauzy Rahman Kosasih ${ }^{1}$, Juhana $^{2}$, Suratinah ${ }^{3}$, Rahayu Dwi Riyanti' ${ }^{4}$, Ika Tri \\ Yanuanika ${ }^{5}$ \\ 1,2,3,4,5Universitas Terbuka \\ email: 1fauzyrahman@ecampus.ut.ac.id, 2juhana@ecampus.ut.ac.id, \\ 3etin@ecampus.ut.ac.id, 4yanti@ecampus.ut.ac.id, 5ika@ecampus.ut.ac.id
}

\begin{abstract}
Abstrak
Program pengabdian kepada masyarakat dengan judul "IbM Pengembangan Taman Baca Digital sebagai Sumber Belajar bagi Masyarakat Pesona 2 Cilebut Barat Kabupaten Bogor" ini bertujuan untuk menumbuhkan dan meningkatkan minat baca dan literasi masyarakat khususnya yang berada di lingkungan mitra yaitu di Pesona 2, Desa Cilebut Barat, Kabupaten Bogor, Jawa Barat. Kegiatan ini melibatkan mitra yang terdiri dari orang tua, pemuda, remaja, dan anak-anak di lingkungan mitra. Kegiatan ini dimulai dengan kunjungan awal untuk menganalisis situasi dan kebutuhan masyarakat di lokasi. Dari hasil kunjungan berhasil diidentifikasi dan disepakati bahwa kegiatan Abdimas difokuskan pada pengembangan taman baca masyarakat (TBM) konvensional berbasis buku cetak. Namun, ketika memasuki bulan Maret 2020, sesuai dengan pengumuman dari Pemerintah Republik Indonesia yang menyatakan bahwa Indonesia juga mengalami pandemi Covid-19 dan mulai diberlakukan pembatasan sosial berskala besar (PSBB), maka perencanaan awal berubah menjadi taman baca digital masyarakat (TBDM) berbasis teknologi. Monitoring dan evaluasi hasil kegiatan Abdimas dilakukan di akhir kegiatan menunjukkan bahwa masyarakat mitra antusias mengikuti kegiatan di TBDM dengan tetap menerapkan protokol kesehatan. Mayoritas para pengunjung TBDM adalah para anak usia sekolah dasar dan sekolah menengah pertama, meskipun pada beberapa kesempatan ada pengunjung yang berasal dari latar belakang guru sekolah menengah kejuruan, mahasiswa, dan pekerja.
\end{abstract}

Kata Kunci: Taman Baca Digital Masyarakat, Taman Baca Masyarakat, Abdimas

\section{Abstract}

This community service program entitled "IbM Digital Reading Corner Development as a Learning Source for the Pesona 2 West Cilebut Community, Bogor Regency" aimed to foster and increase the interest in reading and literacy in the community, especially those in partner environment, namely in Pesona 2, West Cilebut village, Bogor Regency, West Java. This 
activity involves partners consisting of parents, youth, teenagers, and children in the partner environment. This activity began with an initial visit to analyze the situation and needs of the community at the site. From the results of the visit, it was identified and agreed that the community service activities would be focused on developing a conventional printed-based public reading corner. However, when entering March 2020, according to the announcement from the Government of the Republic of Indonesia which stated that Indonesia was also experiencing the Covid-19 pandemic and began to enforce large-scale social restrictions, the initial planning turned into a technology-based community digital reading corner (CDRC). Monitoring and evaluation of the results of these activities carried out at the end of the program, showed that the partner community was enthusiastic about participating in the activities at $C D R C$ while still implementing health protocols. The majority of visitors to CDRC were children of elementary and junior high school age, although on several occasions there were visitors who came from vocational high school teachers, students, and workers.

Keywords: Community Digital Reading Park, Community Reading Park, Community Service

\section{Pendahuluan}

\subsection{Analisis Situasi}

Program Pengabdian kepada Masyarakat (Abdimas) dosen adalah kegiatan yang dilakukan dengan tujuan mulia, salah satunya adalah untuk membantu memecahkan permasalahan yang ada di tengah kelompok masyarakat tertentu. Oleh karena itu, kegiatan Abdimas senantiasa diawali dengan "proses analisis kebutuhan calon mitra agar program yang dijalankan sesuai dengan kebutuhannya (Kosasih dkk., 2018)."

Pada proses penjajakan awal penawaran kerjasama dengan calon mitra, teridentifikasi bahwa di lingkungan calon mitra sedang membutuhkan pengembangan Taman Bacaan Masyarakat (TBM) khususnya bagi generasi pemuda, remaja, dan anak-anak serta tidak menutup kemungkinan bagi para orang tua. Berkaca pada salah satu rekomendasi riset terdahulu yaitu Anna, Mannan, \& Srirahayu (2019) yang merekomendasikan agar "... community empowerment programs should be increased through TBM programs." Artinya bahwa program pengabdian kepada masyarakat salah satunya memang dianjurkan melalui pengembangan TBM. Rekomendasi ini juga didukung oleh penelitian terdahulu lainnya yang dilakukan oleh Khoiruddin, Taulabi, \& Imron (2016), Sitepu (2012) yang menyatakan bahwa “TBM memainkan peranan yang sangat penting dan strategis karena TBM berdiri oleh, untuk, dan berada di tengah-tengah masyarakat."

Hasil penelitian lain dari Misriyani \& Mulyono (2019), Wulandari \& Kusumaningtyas (2017), Septiana (2007) menunjukkan bahwa "potensi gemar membaca masyarakat sebetulnya ada, namun belum didukung fasilitas dan pengelolaan yang memadai sehingga hal tersebut tidak berskembang." Padahal, dari hasil kegiatan Abdimas yang dilaksanakan oleh Syarif \& Eliham (2020), Rahmawati, Nurrahmah, \& Bhakti (2020), 
Falahi dkk., (2019), Aulia (2018), Pramudyo dkk. (2018), dan Wibowo dkk. (2013) menyimpulkan bahwa "Taman Bacaan Masyarakat (TBM) dapat menjadi sarana belajar serta mencari informasi guna meningkatkan minat baca."

Sebelum adanya pernyataan dan kebijakan Pemerintah Republik Indonesia terkait kondisi pandemi Covid-19 di Indonesia, pada mulanya taman baca masyarakat akan berbentuk konvensional dengan memanfaatkan buku dan media cetak. Tetapi, setelah diberlakukannya kebijakan pemerintah terkait penanganan Covid-19, maka masyarakat mitra bersama tim Abdimas UT melakukan tukar pikiran terkait perubahan bentuk TBM konvensional menjadi taman baca digital masyarakat (TBDM) yang memanfaatkan teknologi seperti laptop, internet, pustaka online, sumber bacaan online, dan sumber belajar online. Selain itu, di lingkungan masyarakat mitra pun masih ada beberapa keluarga yang belum memiliki perangkat dan koneksi internet untuk menunjang sekolah daring yang juga diberlakukan oleh pemerintah.

Kegiatan Abdimas berbasis pelatihan pemanfaatan teknologi informasi dan komunikasi kepada masyarakat secara luas sangatlah bermanfaat dan telah dilakukan oleh banyak tim dosen pelaksana Abdimas. Triartanto \& Suriyanto (2019) melakukan Abdimas di bidang "pemanfaatan TIK dengan menggunakan perangkat lunak Microsoft Access bagi masyarakat di wilayah Bekasi - Jawa Barat." Arsi dkk. (2019) melakukan kegiatan Abdimas yang "memanfaatkan TIK yaitu pelatihan dasar komputer dan internet untuk pengembangan SDM di lingkungan Kepolisian Sektor Kedungbanteng." Pada kegiatan Abdimas ini, tim dosen pelaksana memanfaatkan laptop, internet, mesin peramban (browser), dan menu bookmark pada mesin peramban untuk menyimpan sumber bacaan digital.

Adapun pertimbangan dipilihnya calon mitra dari masyarakat Pesona 2 Desa Cilebut Barat, Kabupaten Bogor adalah karena masyarakat tersebut benar-benar membutuhkan program pengembangan TBDM. Kedua, dari sisi infrastruktur penunjang, di lingungan calon mitra telah terdapat bangunan fasilitas umum yaitu balai warga yang dapat menampung peserta TBDM dan perangkat penunjang (laptop, internet, meja, dan lain-lain). Ketiga, tempat yang dijadikan pusat TBDM merupakan tempat memiliki area terbuka yang cukup (tanpa dinding kanan, kanan kiri, dan belakang) sehingga aliran udara menjadi lebih maksimal.

\subsection{Permasalahan Mitra}

Permasalahan terkait pengembangan TBDM pada mitra masyarakat Pesona 2 Desa Cilebut, Kabupaten Bogor diantaranya:

a. Tidak adanya dana untuk mengembangkan TBDM di lingkungan mereka.

b. Belum adanya pembekalan manajemen pengelolaan TBDM bagi mereka.

c. Anak-anak dan remaja belum diarahkan kepada peningkatan minat baca dan literasi.

d. Adanya kebutuhan sebagian masyarakat mitra yang belum memiliki perangkat penunjang pembelajaran daring seperti laptop, internet, dan sebagainya. 


\subsection{Prioritas Pemecahan Permasalahan Mitra}

Mengingat keterbatasan dalam kegiatan $\mathrm{IbM}$ ini, tim pengusul dan mitra sepakat untuk memberikan prioritas pada usaha pemecahan masalah pengembangan TBDM. Prioritas ini diberikan dengan pertimbangan bahwa:

a. Mitra mengharapkan bantuan berupa pengembangan TBDM.

b. Mitra mengharapkan bantuan pelatihan pengelolaan TBDM.

c. Tim Pengusul memiliki kemampuan untuk melatih mengembangkan TBDM dengan mengidentifikasi kebutuhan bahan bacaan yang sesuai dan aman bagi calon mitra, serta perangkat penunjang yang dibutuhkan.

\section{Metode}

\subsection{Pendekatan Pemecahan Permasalahan Mitra}

Pendekatan yang digunakan dalam kegiatan $\mathrm{IbM}$ ini adalah persuasif partisipatif. Dimulai dengan kunjungan dan diskusi dengan mitra di lokasi Pesona 2 Desa Cilebut, Kabupaten Bogor untuk mengidentifikasi berbagai permasalahan yang dihadapi khususnya yang berkenaan dengan pengembangan TBDM. Selama kunjungan, analisis situasi juga dilakukan untuk menilai faktor-faktor yang dapat mempengaruhi pengembangan TBDM di lokasi. Berdasarkan hasil identifikasi permasalahan, dipilih permasalahan yang paling cocok dan memungkinkan untuk dapat ditindaklanjuti dengan usaha pemecahan masalah melalui kegiatan IbM berupa pengembangan dan pelatihan.

\subsection{Pelaksanaan Kegiatan}

Dengan mengusung judul kegiatan yaitu "IbM Pengembangan Taman Baca sebagai Sumber Belajar bagi Masyarakat Pesona 2 Desa Cilebut Barat - Kabupaten Bogor", kegiatan ini dilaksanakan sebagai berikut:
Panitia
: Mitra
Narasumber
: Tim Pengusul
Peserta
: Masyarakat (anak-anak, remaja, pemuda, dan orang tua)
Tempat Kegiatan
: Balai Warga RT09 Pesona 2 Desa Cilebut Barat, Kab. Bogor.
Waktu Kegiatan
a. Pertemuan pendahuluan pada tanggal 17 Juni 2020
b. Pertemuan pertama pada tanggal 18 Juli 2020
c. Pertemuan kedua pada tanggal 25 Juli 2020
d. Pertemuan ketiga pada tanggal 8 Agustus 2020
e. Pertemuan keempat pada tanggal 16 Agustus 2020
f. Pertemuan pendampingan pada tanggal 26 September 2020
g. Pertemuan monev pada tanggal 24 Oktober 2020

\subsection{Prosedur Pelaksanaan Kegiatan}

Kegiatan IbM ini mengikuti prosedur sebagai berikut: 
a. Kunjungan, analisis situasi, dan analisis kebutuhan

b. Konsultasi dan pembuatan proposal IbM

c. Pembentukan kepanitiaan

d. Pengembangan dan Pelatihan

e. Evaluasi

1) Evaluasi Pelatihan

2) Monitoring Luaran

3) Evaluasi Luaran

f. Pelaporan

\subsection{Partisipasi Mitra}

Kegiatan IbM ini sangat bertumpu pada partisipasi mitra dalam hampir seluruh proses kegiatannya. Masukan mitra dalam diskusi dan konsultasi tentang permasalahan yang dihadapi menjadi dasar perencanaan kegiatan. Partisipasi mitra dalam kepanitiaan pengelolaan TBDM diharapkan berdampak pada efektifitas kegiatan dan luaran yang dicapai.

\subsection{Target}

Secara umum, target dari kegiatan IbM ini adalah setelah pengembangan TBM ini masyarakat dapat meningkatkan minat bacanya dan memfasilitasi masyarakat yang belum memiliki fasilitas pembelajaran daring agar mereka dapat tetap belajar daring. Secara khusus, setelah pengembangan dan pelatihan, masyarakat dapat memiliki kompetensi sebagai berikut:

a. Mampu untuk mengelola TBDM.

b. Mampu untuk memanfaatkan bahan bacaan di TBDM sebagai salah satu sumber belajar.

c. Mampu untuk merawat bahan bacaan yang tersedia secara daring.

d. Mampu untuk memperbaharui bahan bacaan sesuai kebutuhan.

Tim terdiri atas dosen pada program studi Pendidikan Bahasa Inggris dan Pendidikan Dasar, Fakultas Keguruan dan Ilmu Pendidikan (FKIP) yang telah memiliki keahlian di dalam bidang pendidikan. Selain itu, dua orang tim merupakan dosen senior yang telah berpengalaman \pm 30 tahun di bidangnya. Dengan pengalaman yang panjang tersebut, maka tim akan mampu melaksanakan usulan program ini dengan baik tentu saja dengan sinergi diantara seluruh personil yang ada.

Pelaksanaan kegiatan Abdimas dengan tema "IbM Pengembangan Taman Baca sebagai Sumber Belajar bagi Masyarakat Pesona 2 Desa Cilebut Barat - Kabupaten Bogor" ini dimulai dengan kegiatan pendahuluan yaitu melakukan kunjungan dan diskusi ke calon mitra terkait kebutuhan pihak mitra yang dapat dikerjasamakan di dalam kegiatan Abdimas tim pengusul. Kegiatan ini dilaksanakan sebelum pengusul menyusun dan mengusulkan proposal kegiatan kepada Lembaga Penelitian dan Pengabdian Masyarakat (LPPM) Universitas Terbuka (UT). Setelah menganalisis 
kebutuhan mitra dan menemukan titik temu dengan mitra, maka selanjutnya tim pengusul mulai menyusun proposal kegiatan dan mengajukannya kepada LPPM-UT.

Pada tahap pelaksanaan, kegiatan Abdimas ini dibagi ke dalam empat tahap yaitu, kegiatan pelatihan kesatu, kedua, ketiga, dan keempat. Pada tahap pertama dilakukan pelatihan pengenalan sumber-sumber bacaan digital yang tersedia di internet. Pada tahap kedua, dilakukan pelatihan pengenalan alat-alat penunjang untuk dapat mengakses sumber bacaan online. Tahap ketiga dilakukan pelatihan pengelolaan TBDM oleh panitia yang dibentuk berdasarkan kesepakatan mitra. Tahap keempat dilakukan pelatihan praktek pemanfaatan TBDM oleh berbagai masyarakat di lingkungan mitra.

Setelah keempat tahap pelaksanaan selesai, selanjutnya dilaksanakan proses monitoring dan evaluasi, serta penilaian untuk mengukur tingkat antusiasme mitra terhadap kegiatan dan program yang dilaksanakan.

\section{Hasil Dan Pembahasan}

Kegiatan Abdimas dengan tema "IbM Pengembangan Taman Baca sebagai Sumber Belajar bagi Masyarakat Pesona 2 Desa Cilebut Barat - Kabupaten Bogor" menghasilkan produk dan data sebagai berikut.

Pertemuan pertama yaitu pertemuan pendahuluan telah menghasilkan hasil analisis kebutuhan mitra yang dapat dikerjasamakan di dalam program Abdimas pengusul yaitu dalam bentuk pengembangan TBM konvensional. Kegiatan dilaksanakan dengan menggunakan diskusi kelompok antara pengusul dan mitra. Kegiatan ini dilaksanakan di tempat mitra yaitu di rumah Ketua RT 09 Pesona Cilebut 2, Kabupaten Bogor - Jawa Barat.

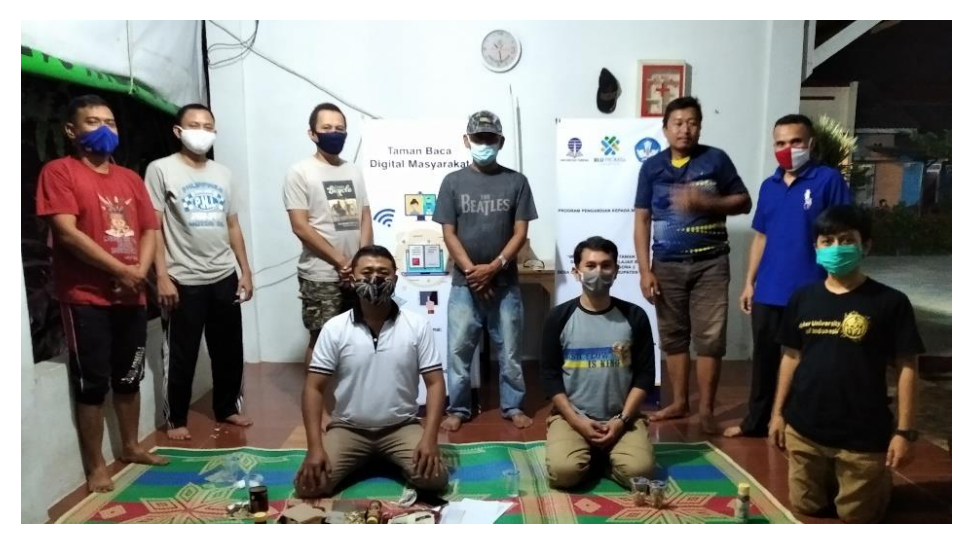

Gambar 1. Pertemuan pendahuluan antara dosen pelaksana Abdimas dengan mitra

Pertemuan kedua yaitu pertemuan pelatihan pertama. Hasil dari kegiatan ini adalah dihasilkannya konsep lain dari yang sebelumnya hanya akan mengembangkan Taman Baca Masyarakat (TBM) konvensional berbasis cetak menjadi Taman Baca Digital Masyarakat (TBDM) berbasis teknologi. Hal ini merupakan hasil dari diskusi antara tim pelaksana Abdimas UT dengan mitra dengan memperhatikan kondisi pandemi 
Covid-19 dan kebijakan Pemerintah Republik Indonesia terkait penanganannya. Selain itu, ditemukan juga data bahwa beberapa keluarga di lingkungan mitra masih ada yang belum memiliki fasilitas penunjang untuk sekolah secara daring. Sehingga, selain TBDM dapat dimanfaatkan untuk membaca sumber bacaan digital juga dapat dimanfaatkan oleh mitra yang membutuhkan untuk sekolah daring. Kegiatan ini dilaksanakan di tempat mitra yaitu di balai warga RT 09 .

Pertemuan ketiga yaitu pelatihan kedua. Pada kegiatan ini, pelaksana Abdimas UT memberikan pelatihan kepada mitra terkait analisis kebutuhan untuk TBDM. Dari hasil analisis bersama mitra dapat diidentifikasi sejumlah perangkat penunjang yang diperlukan yaitu, laptop sebanyak lima unit, meja lesahan sebanyak lima unit, koneksi internet yang stabil dan dapat menampung pengunjung, baterai UPS sebanyak satu unit, dan tetikus (mouse) sebanyak lima unit. Pada tahap ini juga dapat diidentifikasi berbagai sumber bacaan dan pembelajaran daring yang terbuka (gratis) yang dapat diakses oleh pengunjung TBDM). Kegiatan ini dilaksanakan di tempat mitra yaitu di balai warga RT 09.

Pertemuan keempat yaitu pelatihan ketiga. Pada tahap ini, tim pelaksana Abdimas UT memberikan pelatihan penglolaan TBDM. Beberapa pengelola yang telah ditunjuk oleh pihak mitra dilatih untuk membuat bookmark yaitu membuat, menyimpan, menghapus, dan menambahkan daftar catatan penyimpanan alamat laman secara daring pada menu aplikasi seperti Google Chrome, Firefox, dan sebagainya. Setelah pengelola dapat menguasai kemampuan tersebut, selanjutnya tim pelaksana dan mitra menyusun Standar Operating Procedure (SOP) yang mengatur perihal prosedur pengelolaan dan pemanfaatan fasilitas TBDM oleh pengelola dan masyarakt mitra yang akan mengunakan fasilitas TBDM. Pada penyusunan SOP ini pun dimasukkan poin terkait pelaksanaan protokol kesehatan pencegahan penularan Covid-19 oleh pengelola dan masyarakat mitra pengguna TBDM seperti para pengunjung harus dalam keadaan sehat, menggunakan masker, mencuci tangan sebelum dan sesudah menggunakan fasilitas TBDM, menjaga jarak selama di tempat TBDM. Kegiatan ini dilaksanakan di balai warga RT 09.

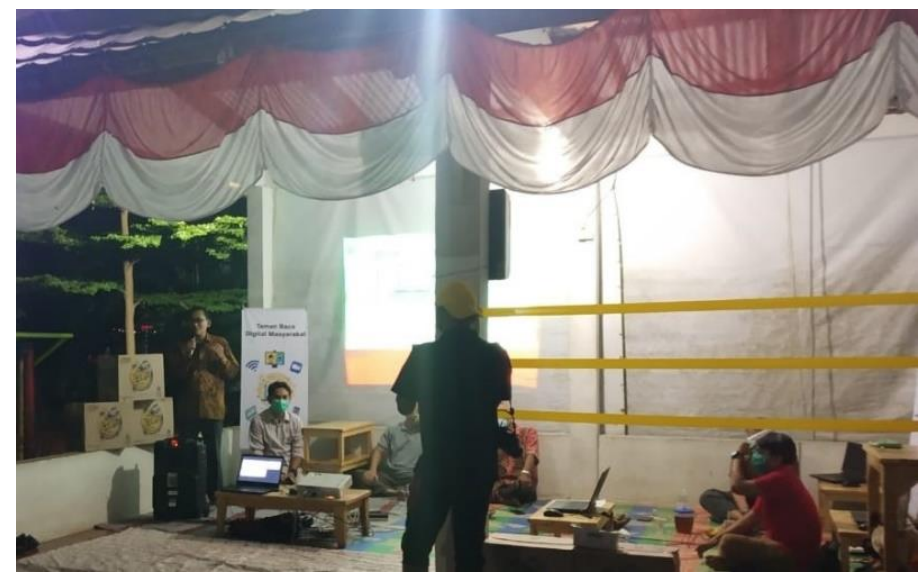

Gambar 2. Pelatihan pemanfaatan sumber bacaan digital bagi pengurus TBDM 
Pertemuan kelima yaitu pelatihan keempat. Pada tahap ini, tim pelaksana dan mitra melaksanakan pelatihan secara langsung kepada pengunjung TBDM yang bertepatan juga dengan pembukaan fasilitas TBDM bagi masyarakat umum di lingkungan mitra. Hasil dari kegiatan tahap ini adalah para pengunjung dapat memanfaatkan fasilitas TBDM secara baik dengan tetap menjalankan protokol kesehatan. Kegiatan ini dilaksanakan di balai warga RT09. Dengan dibukanya fasilitas TBDM kepada masyarakat mitra maka diharapkan akan membantu masyarakat yang membutuhkan akses internet dan akses ke sumber belajar digital. Hal tersebut menjadi esensi kehadiran TBDM seperti yang disarankan oleh Syarif \& Eliham (2020), Rahmawati, Nurrahmah, \& Bhakti (2020), Falahi dkk., (2019), Aulia (2018), Pramudyo dkk. (2018), dan Wibowo dkk. (2013).

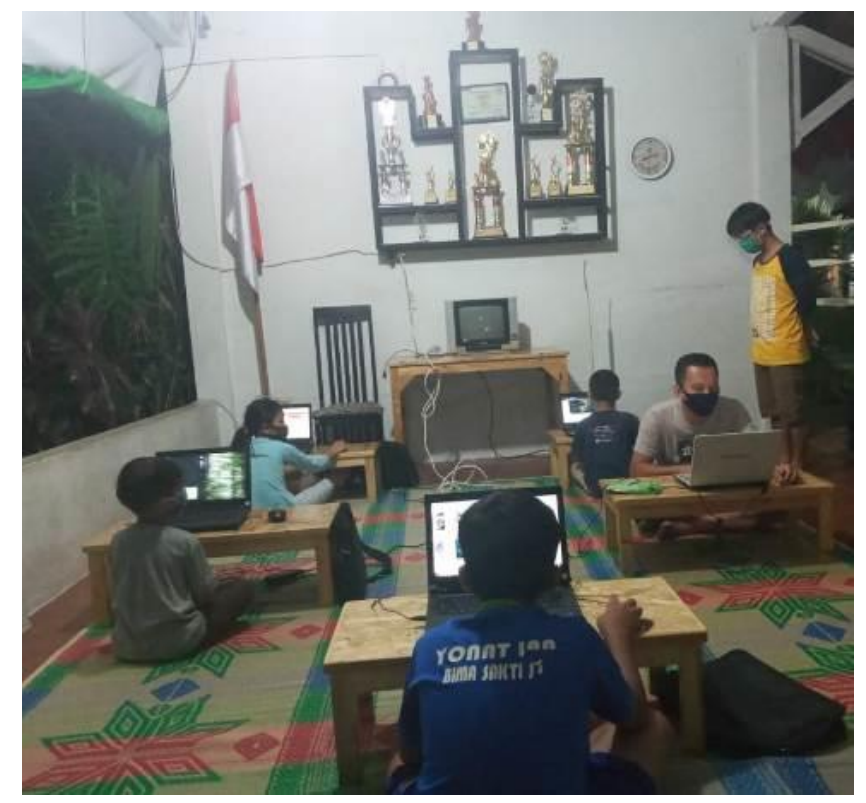

Gambar 3. Pelatihan pemanfaatan sumber bacaan digital Terbuka kepada pengunjung TBDM

Pertemuan keenam yaitu tahap monitoring. Pada tahap ini, tim pelaksana melakukan monitoring pelaksanaan SOP yang diterapkan di tempat TBDM. Hasil dari kegiatan monitoring menujukkan bahwa pengelola dan para pengunjung tetap melaksanakan SOP selama TBDM beroperasi. Pengelolaan TBDM yang baik sangatlah penting dilakukan seperti yang disarankan oleh Misriyani \& Mulyono (2019), Wulandari \& Kusumaningtyas (2017), Septiana (2007),

Pertemuan ketujuh yaitu tahap evaluasi. Pada tahap ini, tim pelaksana melakukan evaluasi terhadap keberhasilan program Abdimas beserta produk yang dihasilkannya. Data dari hasil kegiatan evaluasi menunjukkan bahwa ada beberapa hal yang perlu terus dikembangkan pada alamat sumber bacaan dan pembelajaran daring yang dapat diakses oleh pengunjung. Masih adanya kekurangan bahan bacaan cerita anak yang berbahasa Indonesia yang tersedia secara daring di internet jika dibandingkan dengan cerita anak yang berbahasa Inggris. Pihak pengelola harus tetap mengikuti dan mematuhi perkembangan kondisi penyebaran Covid-19 di daerahnya 
yang diperoleh dari pemerintah atau sumber yang kredibel. Jadi jika daerahnya sedang termasuk ke dalam zona merah, maka secara otomatis fasilitas TBDM ditutup sementara sampai dengan adanya informasi selanjutnya dari pemerintah yang menyatakan bahwa kondisi di daerahnya sudah lebih aman (misalnya, penurunan menjadi daerah zona kuning atau hijau).

Pertemuan kedelapan yaitu tahap penilaian. Pada tahap ini, tim pelaksana melakukan penilaian kepada pihak mitra termasuk pengunjung TBDM. Hasil dari proses penilaian menunjukkan data sebagai berikut.

Tabel 1. Instrumen Penilaian Mitra Kegiatan Abdimas

\begin{tabular}{|c|c|c|c|c|c|}
\hline \multirow{2}{*}{ No. } & \multirow{2}{*}{ Pernyataan } & \multicolumn{4}{|c|}{ Skor } \\
\hline & & 1 & 2 & 3 & 4 \\
\hline 1 & $\begin{array}{l}\text { Pengetahuan yang diperoleh mitra setelah mengikuti } \\
\text { kegiatan }\end{array}$ & & & & $\mathrm{V}$ \\
\hline 2 & $\begin{array}{l}\text { Keterampilan yang diperoleh mitra setelah mengikuti } \\
\text { kegiatan }\end{array}$ & & & & $\mathrm{V}$ \\
\hline 3 & Antusiasme mitra terhadap kegiatan & & & & $\mathrm{V}$ \\
\hline 4 & Partisipasi mitra dalam mengikuti kegiatan & & & $\mathrm{V}$ & \\
\hline 5 & Perilaku mitra selama mengikuti kegiatan & & & $\mathrm{V}$ & \\
\hline 6 & Keaktifan mitra selama mengikuti kegiatan & & & $\mathrm{V}$ & \\
\hline 7 & Tingkat pemahaman mitra setelah mengikuti kegiatan & & & & $\mathrm{V}$ \\
\hline
\end{tabular}

*1 = Sangat Rendah/Kurang, 2 = Rendah/Kurang, 3 = Cukup Tinggi/Baik, 4 = Tinggi/Baik

\section{Simpulan dan Rekomendasi}

Dari pelaksanaan kegiatan Abdimas dengan tema "IbM Pengembangan Taman Baca sebagai Sumber Belajar bagi Masyarakat Pesona 2 Desa Cilebut Barat - Kabupaten Bogor" ini dapat disimpulkan bahwa masyarakat mitra memiliki antusiasmi yang sangat tinggi terhadap kegiatan dan keberadaan TBDM di wilayahnya. TBDM dapat membantu mitra untuk membaca berbagai sumber bacaan dan pembelajaran daring secara terbuka (gratis). Mitra yang memiliki keterbatasan perangkat penunjang pembelajaran daring juga dapat difasilitasi secara gratis di TBDM sehingga mereka merasa sangat terbantu. 
Hasil dari pelaksanaan Abdimas ini merekomendasikan agar daftar alamat laman sumber bacaan dan pembelajaran daring harus selalu diperbaharui atau ditambah agar para pengunjung dapat membaca dan belajar hal baru. Bagi calon pelaksana Abdimas baik dari internal UT maupun dari perguruan tinggi lain agar dapat mempertimbangkan untuk mengembangkan TBDM berbasis teknologi di wilayah calon mitranya karena memang selain untuk membaca sumber bacaan daring juga ada kebutuhan masyarakat yang memiliki keterbatasan atau tidak memiliki fasilitas penunjang untuk pembelajaran daring.

\section{Daftar Pustaka}

Anna, N. E. V., Mannan, E. F., \& Srirahayu, D. P. (2019). Evaluation of the role of society-based library in empowering Surabaya City people. Public Library Quarterly, 0(0), 1-13. https:// doi.org/10.1080/01616846.2019.1616271

Arsi, P., Waningsih, S., Pambudi, A. S., \& Maisa, W. (2019). Peningkatan kualitas SDM dengan pemanfaatan iptek melalui pelatihan komputer dasar dan internet pada anggota Polsek Kedungbanteng. Jurnal ABDIMAS BSI, 2(2), 191-196.

Aulia, M. (2018). Optimalisasi taman bacaan masyarakat dalam menumbuhkan minat baca di kalangan remaja. JURNAL COMM-EDU, 1(3), 146-153. Retrieved from https://journal.ikipsiliwangi.ac.id/index.php/commedu/article/view/734/246

Falahi, R. F., Muflihah, H., Dikdik, D., Devista, N., Firmansyah, D., Invia, C., ... Harits, D. A. (2019). Taman bacaan masyarakat (TBM) untuk meningkatkan minat baca masyarakat. Prosiding Konferensi Pengabdian Masyarakat, 1, 379-382. Retrieved from

http://sunankalijaga.org/prosiding/index.php/abdimas/article/view/242

Khoiruddin, M. A., Taulabi, I., \& Imron, A. (2016). Menumbuhkan minat baca sejak dini di taman baca masyarakat. Journal An-Nafs, 1(2), 291-319. Retrieved from https://www.ejournal.iai-tribakti.ac.id/index.php/psikologi/article/view/295

Kosasih, F. R., Darminah, Suratinah, Riyanti, R. D., \& Juhana. (2018). IbM pemanfaatan open educational resources bagi guru SMA Taruna Terpadu Bogor. Jurnal ABDIMAS BSI, 1(3), 398-405.

Misriyani, M., \& Mulyono, S. E. (2019). Pengelolaan Taman Baca Masyarakat. Journal of Nonformal Education and Community Empowerment, 3(2), 160-172. https://doi.org/10.15294/pls.v2i1.23448

Pramudyo, G. N., Ilmawan, M. R., Azizah, B., Anisah, M., \& Deo, Y. (2018). Inovasi kegiatan taman bacaan masyarakat (TBM). Lentera Pustaka, 4(1), 29-38. Retrieved from https:// ejournal.undip.ac.id/index.php/lpustaka/article/view/17332

Rahmawati, E. Y., Nurrahmah, A., \& Bhakti, Y. B. (2020). PKM menggiatkan literasi 
bahasa inggris dan sains di taman belajar masyarakat RUBIK (rumah belajar Indonesia kreatif). In Widodo MD (Ed.), Seminar Nasional Hasil Pengabdian kepada Masyarakat Universitas Ahmad Dahlan 2020 (pp. 395-400). Retrieved from http://seminar.uad.ac.id/index.php/senimas/article/view/5148

Septiana, R. I. (2007). Perkembangan perpustakaan berbasis komunitas: studi kasus pada rumah cahaya, melati taman baca dan kedai baca sanggar barudak (Universitas Indonesia). Retrieved from http:/ / eprints.rclis.org/10557/1/Skripsi_Ratri_pdf.pdf

Sitepu, B. P. (2012). Pengembangan taman bacaan masyarakat. Jurnal Ilmiah Visi P2TK PAUD NI, 7(1), 42-56.

Syarif, I., \& Eliham, E. (2020). Pengadaan taman baca dan perpustakaan keliling sebagai solusi cerdas dalam meningkatkan minat baca peserta didik SDN 30 Parombean kecamatan Curio. Maspul Journal of Empowerment, 1(1), 109-117. Retrieved from https://ummaspul.ejournal.id/pengabdian/article/view/548/333

Triartanto, A. Y., \& Suriyanto, A. D. (2019). Literasi digital melalui aplikasi Microsoft Access sebagai komunikasi bisnis terhadap perubahan perilaku konsumen (studi pada warga Jatikramat, Bekasi, Jawa Barat). Jurnal ABDIMAS BSI, 2(1), 166-173.

Wibowo, A., Fegumi, M. A., Muchsinin, Nursidiq, F., AlRasyid, P. H., Putra, P. M., ... Harumsari. (2013). Gerakan taman baca "perpustakaan dusun" dari mahasiswa untuk desa. Jurnal Inovasi Dan Kewirausahaan, 2(1), 63-67. Retrieved from https://journal.uii.ac.id/ajie/article/view/7851/6862

Wulandari, C., \& Kusumaningtyas, R. F. (2017). Pembentukan taman baca sebagai wujud pemenuhan hak pendidikan bagi anak-anak di desa Berta, kecamatan Susukan, kabupaten Banjarnegara. ABDIMAS, 21(1), 11-19. Retrieved from https://journal.unnes.ac.id/nju/index.php/abdimas/article/view/10959/6647 